\title{
QUEEN'S
UNIVERSITY
BELFAST
}

\section{Maximizing the Profits of Battery Energy Storage Systems in the Integrated Single Electricity Market}

Mohamed, A. A. R., Morrow, D. J., \& Best, R. (2021). Maximizing the Profits of Battery Energy Storage Systems in the Integrated Single Electricity Market. Paper presented at The 9th International Conference on Renewable Power Generation, Dublin, Ireland. https://doi.org/10.1049/icp.2021.1344

\section{Document Version:}

Peer reviewed version

\section{Queen's University Belfast - Research Portal:}

Link to publication record in Queen's University Belfast Research Portal

\author{
Publisher rights \\ (C) 2021 the Author This manuscript is distributed under a Creative Commons Attribution-NonCommercial-NoDerivs License \\ (https://creativecommons.org/licenses/by-nc-nd/4.0/), which permits distribution and reproduction for non-commercial purposes, provided the \\ author and source are cited.
}

\section{General rights}

Copyright for the publications made accessible via the Queen's University Belfast Research Portal is retained by the author(s) and / or other copyright owners and it is a condition of accessing these publications that users recognise and abide by the legal requirements associated with these rights.

Take down policy

The Research Portal is Queen's institutional repository that provides access to Queen's research output. Every effort has been made to ensure that content in the Research Portal does not infringe any person's rights, or applicable UK laws. If you discover content in the Research Portal that you believe breaches copyright or violates any law, please contact openaccess@qub.ac.uk. 


\title{
MAXIMIZING THE PROFITS OF BATTERY ENERGY STORAGE SYSTEMS IN THE INTEGRATED SINGLE ELECTRICITY MARKET Ahmed A.Raouf Mohamed*, D. John Morrow and Robert J. Best
}

\author{
School of Electronic, Electrical Engineering and Computer Science, EPIC Research Cluster, \\ Queen's University Belfast, BT9 5 AH, Belfast, UK \\ *amohamed06@qub.ac.uk
}

Keywords: Battery Energy Storage System, Energy Arbitrage, Integrated Single Electricity Market, Optimization.

\begin{abstract}
This paper investigates the profitability of deploying battery energy storage systems (BESS) in the modern grid. An optimization tool to maximize revenue from the participation in the Integrated Single Electricity Market (I-SEM) in the island of Ireland is proposed. Real market dataset is used to determine the optimal market participation factors to maximize the returns using bilevel optimization algorithm. The participation in multiple services is explored and highlighted, and the running costs of the BESS are clarified and quantified. The main objective of this paper is to enumerate the financial benefits and opportunities for grid-scale BESS in the island of Ireland. Case studies proved the efficacy of the proposed approach in maximizing the revenue.
\end{abstract}

\section{Introduction}

Reliance on renewable energy distributed generation is essential in order to meet the net-zero carbon target, which results in accelerated deployment of these units [1]. This widescale deployment has increased concern regarding different issues related to the technical operation of the power system such as frequency and voltage problems. The battery energy storage system (BESS) is proposed as an appropriate solution to these issues. The BESS can be used to provide the system with different static and dynamic services that have very fast response which makes their integration beneficial [2]. The installation of BESS is considered as a promising option for the secure accommodation of more renewable energy.

The island of Ireland power system is a renewable energy leader as the wind penetration exceeds $30 \%$ of the electricity demand and has a target of reaching $70 \%$ of total electricity generation from renewable resources by 2030 . The deployment of BESS in the Irish power system is vital in order to meet this target and the later net-zero carbon target by 2050. Despite the many benefits that BESS can provide to the electrical network, there is a much concern about their investment costs. The investment cost of deploying BESS is considerable, however the participation of BESS in different services can be profitable enough to justify their investment.

There are different opportunities in which BESS can participate to achieve high returns. These opportunities are mainly based on country or market specific regulations and the available services. BESS can participate in energy arbitrage, and they are widely used for frequency regulation due to their fast response. Several studies have evaluated and quantified the revenues from the participation of BESS in different services [3], [4]. Other studies focused on optimizing the BESS profits from the provision of multiple services [5], [6]. Maximizing the BESS profits from the participation in different energy markets have been addressed in [7]-[9]. However, maximizing the profits from the participation in the Irish integrated single electricity market (I-SEM) has not been addressed previously.

This paper investigates the available services that BESS can provide in the Republic of Ireland and Northern Ireland. The main contributions of this paper can be summarized as: 1) proposing a novel optimization tool in order to maximize the profits from the participation in I-SEM day-ahead and Intraday markets; 2) determining the optimal participation factor for each market with the aid of previous real market data; 3) quantifying the BESS running costs in Northern Ireland, and 4) discussing the BESS participation in enhanced services and highlighting the major services in order to maximize the revenues. Actual BESS/inverter specifications with practical constraints and limitations are considered.

\section{Integrated Single Electricity Market}

On the island of Ireland, the electricity market was started in 2007 as a single wholesale market, combining two trading areas with different currencies: the Republic of Ireland $(€)$ and Northern Ireland (£). This single electricity market (SEM) which was managed by the single electricity market operator (SEMO) [10], allowed generators and suppliers to submit bids for a certain volume with a price during a specific period. In the SEM, the system marginal price (SMP) is used, which is determined based on the bids and demand using the Market Scheduling and Pricing (MSP) algorithm. However, electricity markets must adapt to cope with radical changes in the electrical system, especially the vast increase in generation from renewables. Thus, the SEM has been replaced by the ISEM which officially went live on 1st October 2018 [11].

The I-SEM provides more flexibility to market participants across the island of Ireland by introducing day-ahead, intraday, and balancing markets, which are cleared before the actual delivery. Additionally, in the I-SEM, the SMP is determined using a cross-border hybrid electricity market integration algorithm (Euphemia) [12]. The simple orders in the day-ahead and intraday markets should consist of price-quantity pairs, with units in $£ / M W h$ and $M W h$ respectively. Each pricequantity pair specifies a price and quantity of electricity in a specified trading period. During the day-ahead market, the trading period is 1 hour, hence for selling, the exchange member should submit the MWh quantity at specific hours with a price. In the Intraday markets, the trading period is 30 minutes. So, the exchange member should submit the MWh 
quantity for a specific 30-minute interval with a price. Additionally, the electricity suppliers enter the market to buy electricity by submitting their price-quantity pairs. After the auction gate closes, all orders are aggregated each delivery hour in the I-SEM and the Euphemia determines the SMP [13].

\section{Maximizing Market Revenue Tool}

This work proposes a maximizing market revenue tool (MMRTool) that can be used by bidders (generator owners) in the I-SEM markets in order to maximize their revenue by determining the optimal quantity with specific trading periods for the day-ahead (DAM) and Intraday (IDA1, IDA2, and IDA3) trading markets. This tool is developed for BESS owners; however, it can be easily modified for any type of generator. The proposed tool adopts a four-layer algorithm to determine the optimal capacity and the time period for bidding at each market to maximize the total revenue.

Each layer represents a market, at each layer, the algorithm determines the optimal capacity and time for bidding in that market. The output from each layer is sent to the next layer in order to calculate the remaining capacity for bidding in the market associated with this layer and to avoid bidding at the same time by an amount that exceeds the maximum BESS capability or exceeds the market available volume for bidding. The algorithm considers the market available volume in each layer and distributes the available capacity optimally to maximize the total revenue from bidding in all these markets. The output of each layer is the optimal bidding quantity in MWh, time period and the expected revenue. The optimization problem inside each layer is treated as linear programming and solved using the linear programming solver Gurobi [14]. The MMRTool requires inputs associated with the BESS/inverter specification and the market data, see Table 1.

Table 1 MMRTool essential inputs

\begin{tabular}{ccc}
\hline Input & Acronym & Description \\
\hline BESS Capacity & $E^{c a p}$ & BESS Capacity in MWh \\
\hline Rated Power & $P_{\max }$ & $\begin{array}{c}\text { BESS maximum output/input } \\
\text { in MW }\end{array}$ \\
\hline $\begin{array}{c}\text { BESS System } \\
\text { efficiency }\end{array}$ & $\mu$ & $\begin{array}{c}\text { The output/input efficiency } \\
\text { of the inverter [\%] }\end{array}$ \\
\hline $\begin{array}{c}\text { Depth of } \\
\text { discharge }\end{array}$ & $D O D$ & $\begin{array}{c}\text { Maximum discharging } \\
\text { capacity percentage [\%] }\end{array}$ \\
\hline $\begin{array}{c}\text { Market } \\
\text { Participation } \\
\text { Factors }\end{array}$ & $\alpha$ & $\begin{array}{c}\text { Factor representing the } \\
\text { selected capacity for each } \\
\text { market in percentage }\end{array}$ \\
\hline $\begin{array}{c}\text { Time period } \\
\text { duration }\end{array}$ & $\tau$ & $\begin{array}{c}\text { Duration of single period (1 } \\
\text { for DAM, 0.5 for IDA) }\end{array}$ \\
\hline SMP & $\rho$ & SMP in £/MWh \\
\hline Volume & $V o l$ & Market available volume \\
\hline
\end{tabular}

The market data are unknown until the market closes and the SEMO announce them. In this work, a forecasting software was used to predict these market values. The GMDH Forecasting and Planning Software [15], was used to forecast the SMP and market volume values by training and testing the GMDH neural network using one-year market data (2018/2019) [16]. The proposed MMRTool model is illustrated in Fig. 1. The objective of the proposed four-layer algorithm is to maximize the revenue in each market which formulated as:

$$
\max \sum_{t=1}^{T_{d}} \rho_{t}\left(P_{t}^{d} \tau\right)
$$

Where $P_{t}^{d}$ is the discharge power (MW) at time $t, \rho_{t}$ is the SMP at time $t$, and $T_{d}$ is the number of discharging periods.

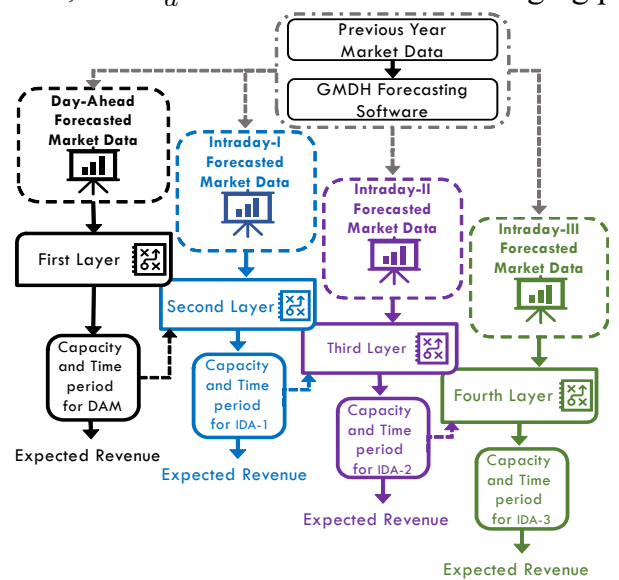

Fig. 1. Proposed MMRTool model

The objective function is subjected to the following constraints:

- BESS System Efficiency: ratio of output-to-input power for the BESS throughout the charge and discharge.

$$
\begin{aligned}
& P_{t}^{d}=\mu P_{t}^{d i s} \\
& P_{t}^{c}=\frac{P_{t}^{c h r}}{\mu}
\end{aligned}
$$

Where $P_{t}^{d i s}$ is the BESS power output and $P_{t}^{d}$ is the inverter power output which used to calculate the bidding capacity and discharging price, $P_{t}^{c h r}$ is the required BESS charging power and $P_{t}^{c}$ is the input power to the inverter which is used to calculate the charging costs.

- Maximum power limit: the output/input power of the BESS must not exceed its predefined limit at any time.

$$
0 \leq P_{t} \leq P_{\max } \quad \forall t \in T, \quad P_{t} \in\left[P_{t}^{d i s}, P_{t}^{c h r}\right]
$$

- Depth of Discharge (DOD): the maximum discharged capacity should not exceed the specific value determined by the $D O D$ percentage value to protect the BESS from damage and to increase its lifespan.

$$
E^{u s}=D o D \times E^{c a p}
$$

Where $E^{u s}$ is the available usable BESS capacity.

- BESS Capacity: The total discharged/charged power cannot exceed the total usable BESS capacity.

$$
\begin{gathered}
\sum_{t=1}^{T} E_{t} \leq E^{u s} \\
E_{t}=P_{t} \tau \quad \forall t \in T, \quad P_{t} \in\left[P_{t}^{d i s}, P_{t}^{c h r}\right]
\end{gathered}
$$

- Market Volume: At any time period, the bidding capacity must not exceed the available market volume for bidding.

$$
E_{t} \leq \operatorname{Vol}_{t}^{m}
$$

Where $m$ represents the market ( 1 for DAM, 2 for IDA 1,3 for IDA2 and 4 for IDA3).

- Market Participation Factors: The reserved BESS capacity for each market / each layer must not exceed the predefined value determined from the market participation factor $(\alpha)$. 


$$
E_{m}^{u s}=\alpha_{m} E^{u s}
$$

The market participation factors are important as they greatly affect the revenue. Selecting the right participation factors for each market is difficult to predict and determine, hence a complex, robust optimization model is required, such as the one proposed in the next section.

\subsection{Optimizing the Market Participation Factors}

The market data for one year from $1^{\text {st }}$ October 2018 to $1^{\text {st }}$ October 2019 [16], is analyzed using a double-layer (bilevel) optimization algorithm to determine the optimal market participation factors. At the outer layer, a global optimization is formulated and solved using the pattern search algorithm from the global optimization toolbox of MATLAB to determine the optimal participation factors that maximize the total revenue from the participation in the four markets. In the inner layer, the same four-layer algorithm (MMRTool) is embedded. At first iteration, initial random participation factor values are used for the inner layer optimization problems. The inner layer calculates the maximum revenue in each market that can be obtained using these factors. Afterwards, the outer layer evaluates the objective function (total revenue) obtained using these initial factors and accordingly the pattern search algorithm updates these factors in order to maximize the total revenue in each iteration as shown in Fig. 2.

The objective function of this bilevel optimization algorithm is formulated as:

$$
\max \left(\sum_{m=1}^{4} \max \left(\sum_{t=1}^{T_{d}} \rho_{t} E_{t}\right)_{m}\right) \mid \sum_{t=1}^{T_{d}}\left(E_{t}\right)_{m}=\alpha_{m} E^{u s}
$$

The optimization variables $x$ represent the market participation factor $\alpha_{m}$, where

$$
\begin{aligned}
& 0 \leq \alpha_{m} \leq 100 \% \\
& \sum_{m=1}^{4} \alpha_{m}=100 \%
\end{aligned}
$$

\section{Case Studies and Results}

The case studies were conducted for a BESS of $4 \mathrm{MWh} / 1 \mathrm{MW}$ of $80 \%$ DOD $\left(E^{u s}=3.2 \mathrm{MWh}\right)$ and $85 \%$ system efficiency. Market data obtained from SEMOpx for one year from $1^{\text {st }}$ October 2018 to $1^{\text {st }}$ October 2019 [16], was used to obtain the optimal market participation factors using the proposed bilevel algorithm. The results are shown in Fig. 3, as shown in Fig. 3, it is difficult to determine an optimal single value for each market, hence, a yearly average value is obtained. The results suggest that the participation factor for Intraday 3 should not exceed $5 \%$, as on many days the available volume for bidding into the market is very small. The participation factors represent the change in the market volume due to the change in demand forecast and the acquired supply through the year. The optimal average values of the factors are as follows: $\alpha_{1}^{D A M}=53 \%, \alpha_{2}^{I D A 1}=26 \%, \alpha_{3}^{I D A 2}=$ $16 \%$, and $\alpha_{4}^{I D A 3}=5 \%$.

The BESS capacity and power rating affect these participation factors. However, for different BESS, these factors will not change much as they depend mainly on each market's volume.
The bilevel algorithm was applied to a 16 MWh / 4 MW BESS with the same efficiency and depth of discharge. The average participation factors for this BESS are determined as follows: $\alpha_{1}^{D A M}=53.8 \%, \alpha_{2}^{I D A 1}=26 \%, \alpha_{3}^{I D A 2}=15.2 \%$,

and $\alpha_{4}^{I D A 3}=5 \%$. Moreover, a $5 \mathrm{MWh} / 10 \mathrm{MW}$ BESS like the one installed at Kilroot Power Station, in Northern Ireland was found to have average participation factors of: $\alpha_{1}^{D A M}=$ $58 \%, \quad \alpha_{2}^{I D A 1}=22.5 \%, \quad \alpha_{3}^{I D A 2}=15 \%, \quad$ and $\alpha_{4}^{I D A 3}=$ $4.5 \%$. These average values will ensure a satisfactory revenue, however, in order to maximize the revenue more, these results can be categorized based on seasons. The percentage values for seasonal factors for the $4 \mathrm{MWh} / 1 \mathrm{MW}$ are shown in Table 2.

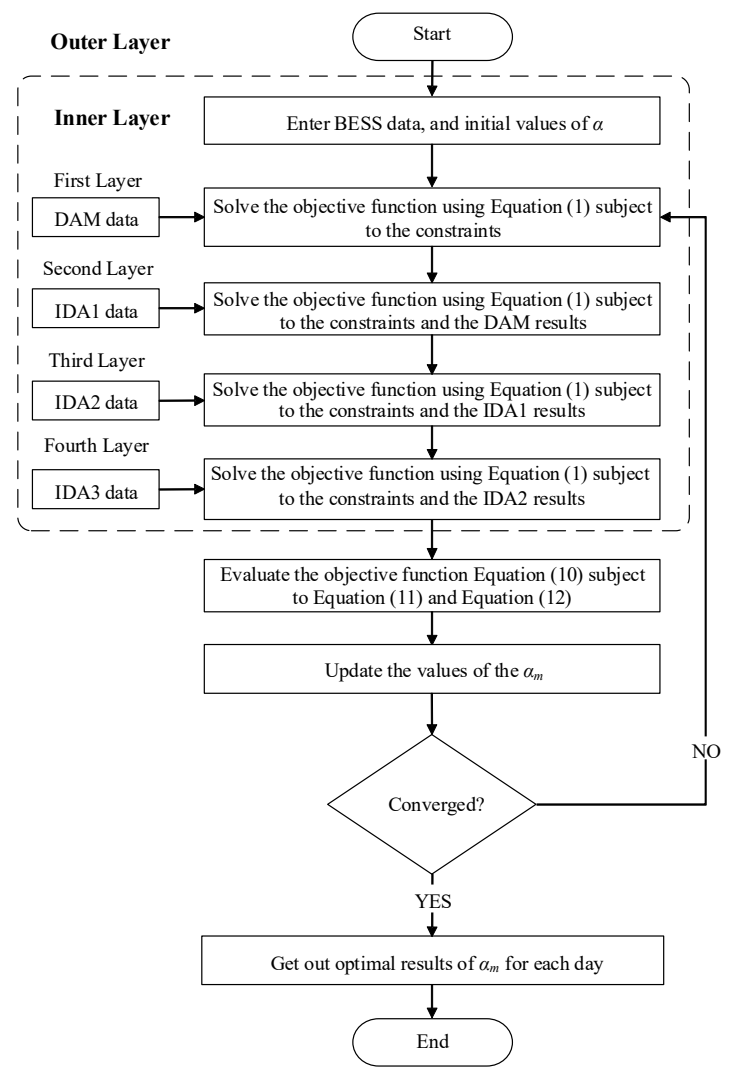

Fig. 2. The bilevel algorithm for market participation factors

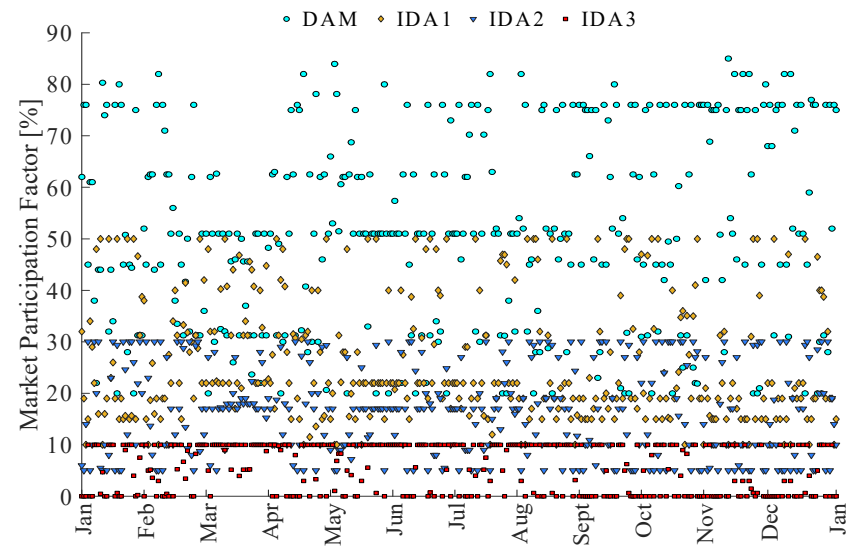

Fig. 3. Optimized market participation factors over the last year

For the sake of comparison, the MMRTool has been used to determine the total yearly earnings from participating in the energy market using different factors. The last year market data 
was used, and six cases were conducted; the first case uses the average factors (AF), the second case uses the seasonal factors (SF) and the other four cases adopt pre-set, non-optimal factors (NF). The results are shown in the Fig. 4 and given in Table 3.

Table 2 Market participation optimal seasonal factors

\begin{tabular}{ccccc}
\cline { 2 - 5 } & $\alpha_{1}^{D A M}$ & $\alpha_{2}^{I D A 1}$ & $\alpha_{3}^{I D A 2}$ & $\alpha_{4}^{I D A 3}$ \\
\hline Spring & 51.2 & 26.7 & 15.7 & 6.5 \\
Summer & 52.3 & 25.6 & 16.6 & 5.6 \\
Fall & 57 & 23 & 16 & 4 \\
Winter & 48 & 28 & 18 & 6 \\
\hline
\end{tabular}

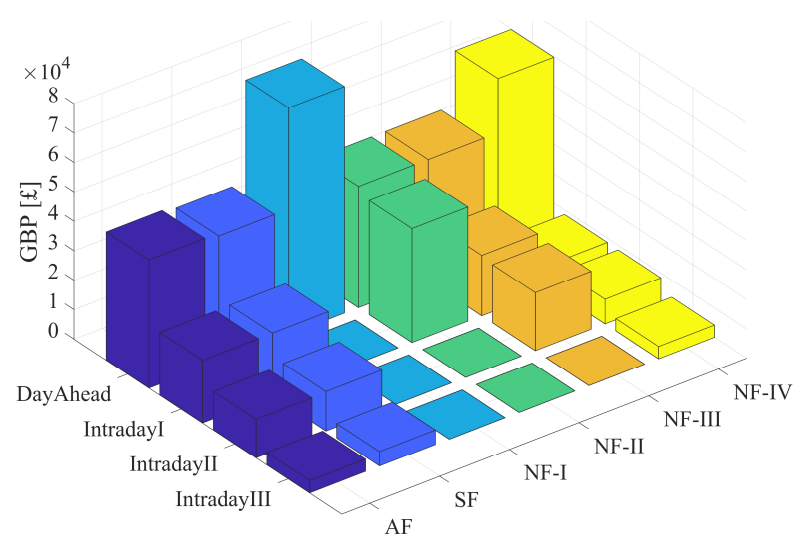

Fig. 4. Yearly return for different market participation factors

Table 3 Yearly expected gain using different factors

\begin{tabular}{cccccc}
\cline { 2 - 6 } & \multicolumn{5}{c}{ Yearly Earnings (£) } \\
\cline { 2 - 6 } & DAM & IDA1 & IDA2 & IDA3 & Total \\
\hline AF & 43,524 & 21,259 & 13,092 & 4,175 & 82,050 \\
SF & 42,520 & 21,407 & 13,434 & 4,893 & 82,254 \\
NF - I & 76,980 & 0 & 0 & 0 & 76,980 \\
{$[100-0-0-0]$} & & & & & \\
NF - II & 41,194 & 38,724 & 0 & 0 & 79,918 \\
{$[50-50-0-0]$} & & & & & \\
NF - III & 41,194 & 20,494 & 19,700 & 0 & 81,388 \\
{$[50-25-25-0]$} & & & & & \\
NF- IV & 59,705 & 8,509 & 8,369 & 4175 & 80,758 \\
{$[75-10-10-5]$} & & & &
\end{tabular}

From the results, the seasonal factors obtained maximum gain. The difference between the total gain using average factors and seasonal factors is only $£ 204$. Yet, for larger BESS capacity, this difference will increase proportionally. To increase this gain further, the proposed bilevel algorithm can be combined with the MMRTool with a robust forecasting algorithm into one tool to determine these factors more accurate on a daily basis. It is also noted from the results that the participation in DAM only is not profitable enough and the participation should be distributed over all the markets for better revenue.

To validate the MMRTool, seven trading days were simulated for the $4 \mathrm{MWh} / 1 \mathrm{MW}$ BESS using the average participation factors. The GMDH software is used to forecast the market data in a day-ahead basis. For each trading day, (1) the MMRTool was used to determine the optimal bidding quantity with the time-period using either the previous year's old market data or the forecasted data. Next, (2) determine the real revenue by applying the values obtained from step (1) to the actual market data (Case-Old) and (Case-Forecast). Finally, (3) the tool is applied to the actual market data to determine the ideal results that could be achieved with perfect forecasting (Case-Ideal). A comparison is made between the revenue obtained between these cases using the absolute percentage error (APE) and the mean absolute percentage error (MAPE) to determine the effectiveness of the proposed tool. The results for the seven trading days are given in Table 4.

Table 4 MMRTool Results for seven different days

\begin{tabular}{|c|c|c|c|c|c|}
\hline & \multicolumn{3}{|c|}{ Daily Earnings (£) } & \multirow{3}{*}{$\begin{array}{c}\text { APE } \\
\text { between } \\
\text { I and III } \\
{[\%]}\end{array}$} & \multirow{3}{*}{$\begin{array}{c}\text { APE } \\
\text { between } \\
\text { II and III } \\
{[\%]}\end{array}$} \\
\hline & Case & Case & Case & & \\
\hline & $\begin{array}{l}\text { Old } \\
\text { (I) }\end{array}$ & $\begin{array}{c}\text { Forecast } \\
\text { (II) }\end{array}$ & $\begin{array}{l}\text { Ideal } \\
\text { (III) }\end{array}$ & & \\
\hline $1 / 10 / 2019$ & 118.6 & 128.6 & 131.7 & 9.94 & 2.38 \\
\hline $10 / 10 / 2019$ & 106.1 & 108.5 & 109.7 & 3.31 & 1.16 \\
\hline $15 / 10 / 2019$ & 131.6 & 140.9 & 148.1 & 11.09 & 4.83 \\
\hline $20 / 10 / 2019$ & 133.0 & 127.7 & 135.2 & 1.63 & 5.56 \\
\hline $25 / 10 / 2019$ & 184.8 & 209.1 & 216.1 & 14.48 & 3.26 \\
\hline $1 / 11 / 2019$ & 113.7 & 125.6 & 146.5 & 22.4 & 14.28 \\
\hline $15 / 11 / 2019$ & 155.2 & 172.9 & 173.1 & 10.33 & 0.12 \\
\hline \multicolumn{4}{|c|}{ MAPE [\%] } & 10.45 & 4.51 \\
\hline
\end{tabular}

As given in Table 4, the cases proved the effectiveness of the proposed methodology and tool in maximizing the profit from participating in the I-SEM markets. The ideal values cannot be achieved as the market data cannot be perfectly forecasted, however, the proposed tool attempts to maximize the revenue using the available data from last year or using the forecasted data. The forecasting tool is generic using the GMDH software and does not consider all the intricacies of this market. However, it is clear that using the forecasted data achieved much better results than using the last year's data as shown in the percentage errors. Yet, in some cases the forecasting accuracy was reduced due to the complex nature of the I-SEM market. Hence, a more focused, robust forecasting algorithm that considers different aspects related to the nature of the Irish system such as high wind generation, interconnections and demand is necessary to obtain better results.

\section{BESS Running Costs}

The BESS running costs include the charging cost (electricity purchasing), operation, maintenance, and other charges associated with the use of the transmission system and distribution network. The BESS charging should be performed during the off-peak time between midnight and 8:00 AM to purchase the electricity at the lowest tariff. The electricity tariff and the charges are different according to the connection voltage level and the distance from the substation. The daily BESS charging cost during the off-peak period should be fairly constant and can be determined using the electricity price $\rho^{\text {chr }}$ and for a number of hours $T_{c}$ as:

$$
\sum_{t=1}^{T_{c}} \rho_{t}^{c h r} P_{t}^{c} \tau
$$

There are many aspects that affect the yearly BESS running costs such as the BESS capacity, technology, location, and connection voltage level. The running costs can be categorized into three main parts shown in Fig. 5, the electricity purchasing cost, the transmission and distribution networks charge, and the 
operation and maintenance cost. The operation and maintenance cost include the operation, maintenance, facilities, insurance, management, degradation, and selfdischarging losses. In Northern Ireland, the average electricity purchasing cost of a $1 \mathrm{MWh}$ battery cycles daily is approximated as 10,950£/year, calculated using an electricity price of $30 \mathrm{f} / \mathrm{MWh}$ during the off-peak period based on the average between the SMP values of last year's market data and the electricity price in [4]. The average transmission and distribution networks charge is estimated as 4,582 £/MW/year [17]. Whilst it is very difficult to determine the operation and maintenance costs as they rely on many factors, however a rough estimate for a lithium-ion BESS would be 5,000 £/MWh/year [4], [18], [19].

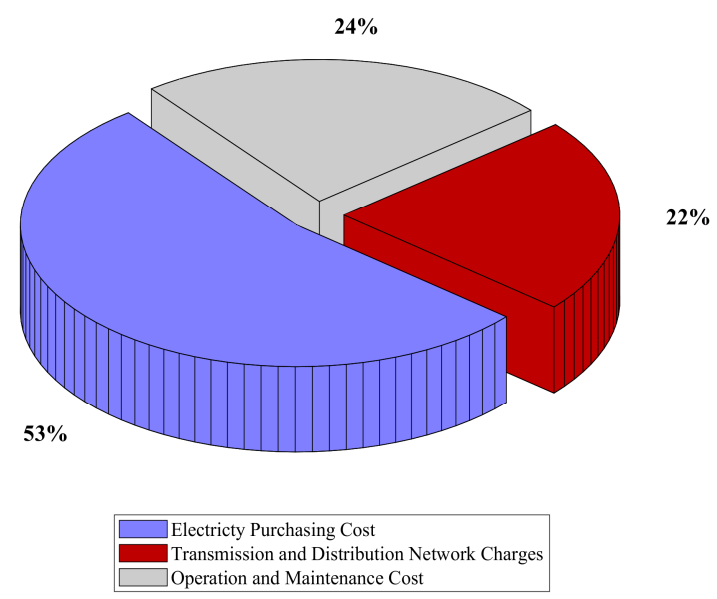

Fig. 5. BESS average yearly running costs in Northern Ireland

The yearly running cost of the $4 \mathrm{MWh} / 1 \mathrm{MW}(80 \% \mathrm{DOD})$ can be then estimated as 59,622 £/year. The expected net revenue will be $22,428 £ /$ year using the yearly return from participating in the I-SEM with average factors from Table III. This revenue may decrease slightly each year due to the degradation based on the BESS technology, specification, and operation environment. Moreover, this revenue can be maximized by using a BESS with high efficiency as well as participating in multiple enhanced services such as DS3 services in the island of Ireland.

\section{Participation in DS3 Services}

To overcome the challenges imposed from increasing the penetration of renewable resources and system nonsynchronous penetration (SNSP), the transmission system operator (TSO) of Ireland and Northern Ireland (EirGrid/SONI) has introduced the DS3 programme. The DS3 programme aims to support the secure operation of the electrical network on the Island of Ireland through the energy evolution. The programme consists of 14 services to support the network with the required static and dynamic actions that maintain system stability and reliability. Mainly, large units participate in these services with long contracts. Additionally, the admission into these services is not easy and includes many assessments. However, medium size units should have an important role in this paradigm to increase the system stability and supply security. While there is insufficient space to detail the DS3 services in this paper, full details may be found in [20].
Because of the capability of BESS to provide 13 of the 14 DS 3 services, their deployment is increasing rapidly. The revenue from the BESS can be maximized by participating in the DS3 services. Additionally, the lifespan of the BESS may increase as most of these services require only a reserve capacity. For standby use, the BESS would require fewer cycles per year, which will also reduce the maintenance and operation costs. Noteworthy, equipping the BESS with a larger inverter will allow the continuous participation in the reactive power services, especially the Steady State reactive Power (SSRP). Fig. 6 shows the total yearly payment to the participants for providing the main DS3 services, with the DS3 services payment rates for each MWh shown in the same figure [21], [22]. This represents the overall participation of different units, including the existing BESS, in the DS3 services. Fig. 6 should be considered by the DS3 participants to determine the profitable services to maximize their revenues.

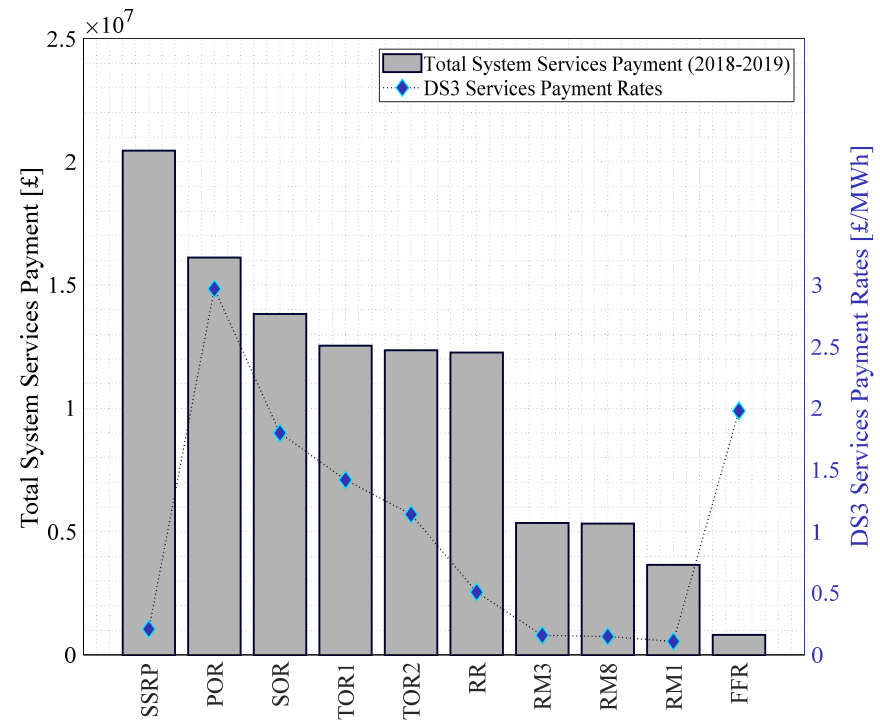

Fig. 6. DS3 services yearly payment to the participants, and DS3 services payment rates for each MWh [21], [22]

BESS as part of aggregated capacities should participate in the I-SEM market and DS3 services to increase the returns as on many occasions the available volume in the market may restrict the participation with the full capacity. The received payment for DS3 services can be calculated for each service as:

Trading Period Payment $=$ Available Volume $\times$ Payment Rate

$\times$ Trading Period Duration $\times$ Scaling Factor

Where:

- Available Volume (MW) is the Available Volume of the Providing Unit in respect of service [23].

- Payment Rate is the Payment Rate (£/MWh) [21].

- Trading Period Duration (expressed in hours).

- Scaling factor is a factor can be determined using four different scalars as:

Scaling Factor $=$ Product Scalar $\times$ Temporal Scarcity Scalar

$\times$ Locational Scalar $\times$ Performance Scalar

These scalars are important in determining the payment by evaluating the unit capability, performance, location, and the need of service. Each scalar can be determined using a set of rules and assumptions which can be found in [23]. Scaling scalars and quantifying the yearly revenue from the 
participation of BESS in the DS3 services has been comprehensively addressed in [24].

\section{Conclusions and Discussion}

This paper explored the economic viability of deploying gridscale BESS. The paper focused on the participation in energy arbitrage and DS3 services in Northern Ireland. A powerful tool of four layers has been proposed to maximize the revenue from participating in the island of Ireland's I-SEM. A bilevel stochastic optimization problem is solved to determine the optimal market participation factors. The cases proved the effectiveness of the proposed approach in maximizing the total revenue. However, future research should focus on developing a robust market forecasting algorithm to predict the market data precisely to increase the reliability of using the MMRTool.

The BESS running costs in the UK were quantified using real data and project reports. These costs can be reduced by participating in multiple ancillary services as the degradation rate will be reduced, which will increase the lifespan and available cycles as well as reducing the charging cost as the capacity will be used as a reserve in most services. Additionally, installing an appropriate inverter will leverage the returns by providing reactive power products. The work was extended to investigate the opportunities of BESS in providing enhanced DS3 services. The BESS owners should strike a balance between participating in the I-SEM market and DS3 services to leverage the maximum returns.

There is a huge need for enhanced services at the distribution level to improve the operation of the electrical network. It is advised that distribution network operators and utility regulators should work on proposing and regulating services that can be delivered by prosumers' medium / small scale generation units and loads. The prosumers will participate in the overall process which will increase their profit, while assisting in solving the future network's expected problems which will be exacerbated by high deployments of low carbon technologies. These technologies will cause network congestion leading to reverse power flow, voltage violations and overloading of cables and transformers. These problems can be solved by providing some services such as voltage regulation, peak shaving, and demand side management.

\section{Acknowledgments}

The authors acknowledge the support from SPIRE2 (Storage Platform for the Integration of Renewable Energy) project. This work is part of SPIRE2 project, supported by the European Union's INTERREG VA Programme, managed by the Special EU Programmes Body (SEUPB). The views and opinions expressed in this paper do not necessarily reflect those of the European Commission or the SEUPB.

\section{References}

[1] Mohamed, A.A.R., Morrow, D.J. and Best, R.: 'The Deployment of Low Carbon Technologies in Modern Distribution Networks', IEEE PES Innovative Smart Grid Technologies Europe (ISGTEurope), Bucharest, Romania, 2019, pp. 1-5, doi: 10.1109/ISGTEurope.2019.8905643

[2] Luo, X., Wang, J., Dooner, M. and Clarke, J.: 'Overview of current development in electrical energy storage technologies and the application potential in power system operation', Applied energy, 2015, 137, pp.511-536.
[3] Schmidt, O., Hawkes, A., Gambhir, A. and Staffell, I.: ' The future cost of electrical energy storage based on experience rates', Nature Energy, 2017, 2, (8), pp.1-8.

[4] Sidhu, A.S., Pollitt, M.G. and Anaya, K.L.: 'A social cost benefit analysis of grid-scale electrical energy storage projects: A case study', Applied energy, 2018, 212, pp.881-894.

[5] Avendano-Mora, Manuel, and Ernst H. Camm.: 'Financial assessment of battery energy storage systems for frequency regulation service'. IEEE power \& energy society general meeting, Denver, CO, July 2015, pp. 1-5.

[6] Zhang, Y.J.A., Zhao, C., Tang, W. and Low, S.H.: 'Profitmaximizing planning and control of battery energy storage systems for primary frequency control', IEEE Transactions on Smart Grid, 2016, 9, (2), pp.712-723.

[7] Nguyen, T.A., Byrne, R.H., Concepcion, R.J., Gyuk, I.: 'Maximizing revenue from electrical energy storage in MISO energy \& frequency regulation markets'. IEEE Power \& Energy Society General Meeting, 2017, pp. 1-5.

[8] Lackner, C., Nguven, T., Byrne, R.H., Wiegandt, F.: 'Energy storage participation in the german secondary regulation market'. IEEE/PES Transmission and Distribution Conference and Exposition (T\&D), 2018, pp. 1.

[9] Byrne, R.H., Nguyen, T.A., Copp, D.A., Concepcion, R.J., Chalamala, B.R., Gyuk, I.: 'Opportunities for energy storage in caiso: Day-ahead and real-time market arbitrage'. IEEE International Symposium on Power Electronics, Electrical Drives, Automation and Motion, 2018, pp. 63-68.

[10] 'Single Electricity Market Operator', http://www.sem-o.com/

[11] 'SEM Committee, Quick Guide to the I-SEM', https://www.semcommittee.com/sites/semc/files/mediafiles/ISEM\%20quick\%20guide 1.pdf

[12] 'EUPHEMIA Pūblic Description', https://www.nordpoolgroup.com/globalassets/downloadcenter/pcr/euphemia-public-description.pdf

[13] 'SEMOpx Operating Procedure', https://www.semopx.com /documents/general-publications/SEMOpx-OperatingProcedures.docx

[14] 'L. L. C. Gurobi Optimization, Gurobi Optimizer Reference Manual 2019', http://www.gurobi.com

[15] 'GMDH Shell for Data Science: GMDH Shell documentation, New York: GMDH LLC', https://gmdhsoftware.com/.

[16] 'SEMOpx Document Library', https://www.semopx.com /market-data/document-library/

[17] 'SONI TUoS Statement of Charges', http://www.eirgridgroup.com/sitefiles/library/EirGrid/CERApproval-Statement-of-Charges-2018_19.pdf

[18] Brinsmead, T.S., Graham, P., Hayward, J., Ratnam, E.L. and Reedman, L.: 'Future energy storage trends: An assessment of the economic viability, potential uptake and impacts of electrical energy storage on the NEM 2015-2035'. CSIRO, Australia. Report No. EP 155039, 2015.

[19] Aquino, T., Roling, M., Baker, C. and Rowland, L.: 'Battery Energy Storage Technology Assessment'. Platte River Power Authority: Fort Collins, CO, USA, November 2017.

[20] 'DS3 Services', http://www.eirgridgroup.com/how-the-gridworks/ds3-programme/

[21] 'SONI DS3 System Services Statement of Payments', http://www.soni.ltd.uk/media/documents/DS3-SS-Statement-ofPayments-2019-20.pdf

[22] 'SONI Ancillary Services Report 2018/2019', http://www.soni.ltd.uk/media/documents/AS-OSCReport_2018-19.pdf

[23] 'DS3 System Services Agreement', http://www.eirgridgroup.com/site-files/library/EirGrid/NI-DS3System-Services_Regulated-Arrangements_final.pdf

[24] Brogan, P., Best, R., Morrow, D., Duncan, R. and Kubik, M.L.: 'Stacking Battery Energy Storage Revenues with Enhanced Service Provision', IET Smart Grid, 2019. 